\title{
Impact of training in Advanced Cardiac Life Support (ACLS) in the professional career and work environment
}

\author{
Impacto da capacitação no Suporte Avançado à Vida em \\ Cardiologia (SAVC) na carreira profissional e no ambiente \\ de trabalho
}

Lunia Sofia Lima Azevedo ${ }^{1}$

Lucas Gaspar Ribeiro ${ }^{2}$

André Schmidt ${ }^{1}$

Antônio Pazin-Filho ${ }^{1}$

\footnotetext{
${ }^{1}$ Departamento de Clínica Médica, Faculdade de Medicina de Ribeirão Preto (FMRP), Universidade de São Paulo (USP). Av. Bandeirantes 3900, Monte Alegre. 14049-900 Ribeirão Preto SP Brasil. lucasgasparribeiro@ gmail.com

${ }^{2}$ Fundação de Amparo ao Ensino, Pesquisa e Assistência (FAEPA), Hospital das Clínicas, FMRP, USP. Ribeirão Preto SP Brasil.
}

\begin{abstract}
We sought to evaluate the impact of Advanced Cardiac Life Support (ACLS) training in the professional career and work environment of physicians who took the course in a single center certified by the American Heart Association (AHA). Of the 4631 students (since 1999 to 2009), 2776 were located, 657 letters were returned, with 388 excluded from the analysis for being returned lacking addressees. The final study population was composed of 269 participants allocated in 3 groups ( $<3$ years, 3-5 and $>5$ years). Longer training was associated with older age, male gender, having undergone residency training, private office, greater earnings and longer time since graduation and a lower chance to participate in providing care for a cardiac arrest. Regarding personal change, no modification was detected according to time since taking the course. The only change in the work environment was the purchase of an automated external defibrillator (AED) by those who had taken the course more than 5 years ago. In multivariable analysis, however, the implementation of an AED was not independently associated with this group, which showed a lower chance to take a new ACLS course. ACLS courses should emphasize also how physicians could reinforce the survival chain through environmental changes.
\end{abstract}

Key words Cardiac arrest, Advanced Cardiac Life Support, Social responsibility
Resumo Buscou-se avaliar o impacto do curso de Suporte Avançado a Vida em Cardiologia (SAVC) na carreira e no ambiente profissional de médicos formados em um centro de treinameto certificado pela American Heart Association (AHA). De 4631 estudantes (desde 1999 até 2009), 2776 foram encontrados, 657 cartas retornaram, sendo 388 excluidas da análise devido à não localização do endereço. A população final estudada foi composta por 269 participantes alocados em 3 grupos (<3 anos, 3-5 anos $e>5$ anos). Tempo maior de treinamento foi associado a sexo masculino, ter feito residência médica, de idade maior, melhores salários e mais tempo de formação, também menor chance de participar de um atendimento de parada cardíaca. No quesito mudança pessoal, nenhuma modificação foi detectada independentemente do tempo de curso. A única mudança no local de trabalho foi a implantação do desfibrilador externo automático (DEA) por aqueles que terminaram o curso há mais de 5 anos. Na análise multivariada, entretanto, a implementação de DEA não foi associada independentemente nesse grupo, que mostrou menor chance de repetir o curso. Os cursos SAVC deveriam enfatizar a forma como os médicos poderiam reforçar as mudanças no trabalho, melhorando a cadeia de sobrevida.

Palavras-chave Parada cardiaca, Suporte Avançado à Vida em Cardiologia, Responsabilidade social 


\section{Introduction}

Despite all the efforts of the last few decades, there still is no precise estimate of the incidence of cardiac arrest or its survival rate. Multiple factors are responsible for this situation, including the reduced incidence of coronary disease - directly correlated to cardiac arrest - but one of the major contributing factors is the lack of a well-structured database that would permit trend evaluation ${ }^{1}$.

This also complicates the assessment of the impact of Basic and Advanced Life Support courses proposed by institutions such as the American Heart Association (AHA) as strategies aiming at strengthening the survival chain. There is evidence that Advanced Cardiac Life Support (ACLS) courses are effective for the improvement of in-hospital patient care and survival ${ }^{2,3}$. There is also evidence of the effectiveness of the Basic Life Support (BLS) course, which, however, involves varying rates of post-training retention ${ }^{4-8}$. All of these efforts may not be strengthening the survival chain in a uniform manner and the question of retention becomes a fundamental point regarding the maintenance of the conquests ${ }^{5,8-10}$.

The ACLS course is based on active participation and skills development in basic life support, management of cardiac arrest, identification and treatment of acute coronary syndromes and other life-threating situations ${ }^{11}$. Despite widespread in Brazil since 1996, there is still lack of training of a growing population pf physicians and revalidation courses are a scarce.

The Center for Training in Life Support(CTLS) is linked to and regularly audited by the AHA and has been offering courses in various modalities since 1999, having contributed to the training of more than 5000 professionals in ACLS ${ }^{12}$. The courses had been taught both locally in several other Brazilian states. For all these courses, the CTSV keeps files containing the demographic variables of the participants (gender, age, professional training, time of activity, etc), the place where the course occurred and the performance of the participants in the theoretical and practical evaluations applied. These data open the possibility to interview these professionals in order to assess the impact of the ACLS course on their careers and on the social environment where they are working.

From the CTLS data base, we tried to access all participants in the ACLS since 1999 to 2009 to evaluate the impact of the course could have had on their short, medium and long term pro- fessional life using a dedicated self-applied questionnaire.

\section{Methodology}

We developed a self-applicable written survey questionnaire for the purpose of the study. Since the Research Ethics Committee of our institution requested that all participants provided written signed term of consent, the questionnaire was designed to be self-applicable and sent to and back through post service. The questionnaire was designed to obtain categorical answers regarding three domains: A) Participant's Profile (10 questions), b) Impact of the ACLS Course on his(her) professional practice (5 questions) and 3) Impact of the ACLS Course on his(her) work environment (5 questions). All questions required only a mark (X) for answer, except by two questions regarding the type of residency and which was the higher grade of post-graduation the participant has completed. The questions aren't correct or incorrect answer, because of this, wasn't use the psychometrics dates.

After the basic questionnaire was elaborated, we submitted it to a group of 30 voluntaries to evaluate its psychometric properties. After the input of these group, we made all the corrections necessary and used another ACLS training center linked to ours to test the questionnaire in a group of 50 voluntaries who had completed the course in the last 90 days. We have chosen this group for pilot study because they represent the same profile of the participants in our database. The 90 days interval was chosen because the participants were still living in the address provided for course subscription. We have 45 answers and none left any question without a mark. With this process we reached the final version of the questionnaire (Chart 1) which was sent to all professionals, together with a consent form and a stamped envelope for the return of the filled out documents.

Based on the CTSV files, we located the addresses of 4631 doctors trained with ACLS during the period from 1999 to 2009. When addresses were not available or were outdated, the information was obtained from the Regional Council of Medicine of the respective states. When the material was not returned, the participant was contacted by telephone and the questionnaire was sent again. Questionnaires returned by the Post Office with the indication that the address was not found were considered to represent a loss. If 
Chart 1. Self-applicable questionnaire.

After reading the Term of Informed Consent of the study "Impact of the Advanced Cardiac Life Support (ACLS) course on the change in professional practices related to emergency", please carefully read the questionnaire below and check with an $(\mathrm{x})$ the correct reply for each question.

\section{Identification}

DATE OF BIRTH _________ $(\mathrm{dd} / \mathrm{mm} /$ yyyy $)$

SEX 1. Male 2. Female

\section{A - Participant's Profile}

1) Do you have your Medical Residency? ( )yes ( )no 1.1) which?

2) Postgraduate courses (Master's, Doctorate or Postdoctorate)? ( )yes ( )no

2.1) If yes, provide the higher grade

3) Do you work in a hospital? ( )yes ( )no

4) Office? ( )yes ( )no

5) Number of jobs you hold ( ) 1 or 2 ( )3 or more

6) On average, how many hours per week do you work in emergency services? ( ) $<6$ ( ) 6-12 ( ) $>12$

7) In the care of how many cardiac arrests did you participate in the last year? ( ) $<5$ ( ) 5-10 ( ) >10

8) Income: ( )up to 5 salaries ( ) 5 to 10 salaries ( )more than 10 salaries

9) Years since obtaining your MD: ( ) up to 5 years ( ) 5 to 10 years ( )more than 10 years

10) Participation in courses or congresses of your specialty:

( )less than 1 per year ( )at least 1 per year ( )more than 2 per year

\section{B - Impact of the ACLS Course on your professional practice}

After you took the course:

1) Did you perceive a change in your medical practice? ( )yes ( )no

2) Did you experience more assurance in providing care? ( )yes ( )no

3) Did you perform a more important role in team care or did you receive greater recognition on the part

of your colleagues? ( )yes ( )no

4) Did you perceive greater certainty about the conducts to be followed, for example, in the care of a patient with cardiorespiratory arrest? ( )yes ( )no

5) Did you take other ACLS courses in order to keep up to date? ( )yes ( )no

\section{C - Impact of the ACLS Course on your work environment}

After you took the course, did you improve your work environment as indicated below:

1) Purchase of an AED or defibrillator ( )yes ( )no

2) Purchase of materials such as bag masks, gurneys or oxygen devices? ( )yes ( )no

3) Reform of visiting rooms? ( )yes ( )no

After you took the ACLS course did you encourage:

4) The training of the team with which you work or of your specialty colleagues? ( )yes ( )no

5) The placement of AEDs in public spaces ( )yes ( )no

the no answer was sent back we considered it a loss. We only tried to contact physicians, since other professionals were not allowed to take the course during the study period.

To all these professionals were sent a self-applied questionnaire, along whit the informed consent and an envelope stamped from returning the documents after filling (Chart 1). The questionnaires were sent by regular mail as requested by the Research Ethics Committee of the University Hospital. This request prevented us from using the world wide web for data collection.

The initial goal was to have the answers to all course participants, all doctors. The courses were made from the CTLS team, either in Ribeirão Preto or in other cities served by the CTLS. As not all doctors live in the State of São Paulo, the letters was sent to all Brazilian States. Only doctors participants. because the largest number of students of the course in Ribeirão Preto are doctors, and thus a significant sample. The course is also for nurses.

The questionnaire was developed by the researchers in order to facilitate adherence (be self-applicable). The participants were distributed into 3 groups according to the time they took the course of ACLS - less than 3 years, 3-5 years and more than 5 years. We included all question- 
naires who have all answers completes, beyond the informed consent terms and excluded not returned or unfulfilled questionnaires and those without signed informed consent term.

The project was approved by the Research Ethics Committee of the University Hospital, and Certificate of Presentation for Ethical Consideration (CAAE in the Portuguese acronym).

The categorical variables were reported as percentage and the continuous variables as mean and standard deviation, as measures of central tendency. The categorical variables were compared by the Fisher or Chi-Square test and the unpaired continuous variables were compared by the Student t-test or by analysis of variance (ANOVA) or their corresponding nonparametric tests. Multiple logistic regression was used for multivariable analysis, based on the incremental model technique. The level of significance was set at $\mathrm{p}<0.05$ for all tests. The Stata software version 10 was used for data analysis and for the construction of graphs.

\section{Results}

Of the 4631 students who took the ACLS course, 2776 were located (59.9\%). A total of 657 letters (23.6\% of those sent) were returned, with 388 (59\%) excluded from the analysis for being returned due to failure to locate the addressees by mail or telephone contact. The final study population was composed of 269 participants who provided a complete answered questionnaire (41.1\% of those returned and $9.7 \%$ of those mailed). These response rate is acceptable and expected in the survey research using written sent material through mail, as detailed elsewhere ${ }^{13}$. Considering the sample and methodology, results less than $10 \%$ of answers are acceptable for this type of research.

The participants were representative from the 5 regions of Brazil, including the states: Alagoas(1), Amazonas(2), Bahia(1), Distrito Federal(3), Goiás(5), Minas Gerais(25), Paraná(38), Pernambuco(2), Rio Grande do Norte(1), Santa Catarina(9), São Paulo(182).

The results of univariate analysis according to time when the course was taken are listed in Tables 1 and 2. The results are only about 269 participants who returned correctly the survey, all are physicians trained since 1999 to 2009 in ACLS course from CTSV team (Ribeirão Preto).

Figure 1 illustrates the predictive variables for the participation in a new ACLS course. Figure
2 illustrates the variables that involved a greater chance for a doctor who had taken an ACLS course to act in his community in order to introduce the automated external defibrillator (AED) in public places.

\section{Discussion}

The present data demonstrate that a longer time of training was associated with older age, male gender, residency, working in an office, greater earnings and longer time since graduation. This population was also associated with a lower chance to participate in providing care for a cardiac arrest. Regarding personal change, no modification was detected according to time since taking the course, although all respondents reported that they felt more assurance about patient care. In contrast, those who had taken the course more than 5 years ago were involved in greater changes in their work environment, although statistically significant data were obtained only regarding the purchase of an automated external defibrillator (AED). In multivariable analysis, however, the implantation of an AED in the community was not independently associated with this group, which showed a lower chance to take a new ACLS course. But the results in absolute numbers, confirm that professionals took the course of five years or more are able to change their place of work, and this fact is very important forward therapeutic response to a CPR.

In view of the difficulty in retaining and updating the information and the models of the course, the recommendation is to revalidate the ACLS course every two years. However, the present data indicate that the revalidation of the course was pursued only by professionals who had attended more than five events after the course and who worked in an office, and that, the longer the time after the course, the lower the chance of revalidation. Thus, a doctor only seeks revalidation if he has been exposed to frequent events or if he works in a private office.

The first condition is to be expected, but it is interesting to observe that what led a doctor to seek revalidation was the participation in events and not the number of hours he works in emergency units. There seems to be the need for frequent emotional experience in CPR care in order to seek revalidation, a fact that may not occur in non-referenced emergency services. We opted to include in incremental models the variables regarding assurance in providing care in order to 
Table 1. Profile of the participants in the Advanced Cardiac Life Support course according to time since taking the course, based in the survey.

\begin{tabular}{|c|c|c|c|c|c|}
\hline \multicolumn{2}{|c|}{ Time since the ACLS course } & $<3$ years $(84)$ & $1-5$ years $(66)$ & $>5$ years $(119)$ & p-value \\
\hline \multicolumn{2}{|c|}{ Age (standard deviation) } & $36.7(10.49)$ & $41.2(12.77)$ & $43.3(9.52)$ & $<0.01$ \\
\hline \multicolumn{2}{|l|}{ Male gender } & $45(53.5 \%)$ & $36(54.5 \%)$ & $90(75.6 \%)$ & $<0.01$ \\
\hline \multicolumn{2}{|c|}{ Residence in the State of São Paulo } & $55(65.4 \%)$ & $45(68.1 \%)$ & $83(69.7 \%)$ & 0.813 \\
\hline \multicolumn{2}{|c|}{ Medical residency } & $58(69.0)$ & $58(87.8)$ & $113(94.9)$ & $<0.01$ \\
\hline \multicolumn{2}{|c|}{ Medical residency in a clinical area } & $26(30.9)$ & $22(33.3)$ & $60(50.4)$ & $<0.01$ \\
\hline \multirow[t]{3}{*}{ Place of work } & Hospital & $75(89.3 \%)$ & $60(90.9 \%)$ & $101(84.8 \%)$ & 0.45 \\
\hline & Office & $37(44.0 \%)$ & $46(69.7 \%)$ & $90(75.6 \%)$ & $<0.01$ \\
\hline & Health unit & $30(35.7 \%)$ & $29(43.9 \%)$ & $39(32.7 \%)$ & 0.315 \\
\hline \multicolumn{2}{|l|}{ Only has 1 (one) job } & $58(69.0 \%)$ & $38(57.5 \%)$ & $65(54.6 \%)$ & 0.108 \\
\hline \multirow[t]{3}{*}{ Estimated salary } & $<5$ salaries & $39(46.4 \%)$ & $16(24.2 \%)$ & $13(10.9 \%)$ & $<0.01$ \\
\hline & 5-10 salaries & $22(26.1 \%)$ & $26(39.3 \%)$ & $37(31.0 \%)$ & \\
\hline & $>10$ salaries & $23(27.3 \%)$ & $24(36.3 \%)$ & $69(57.9 \%)$ & \\
\hline \multirow[t]{3}{*}{ Time since graduation } & $<5$ years & $43(51.1 \%)$ & $14(21.2 \%)$ & $1(0.8 \%)$ & $<0.01$ \\
\hline & $5-10$ years & $14(16.6 \%)$ & $24(36.3 \%)$ & $25(21.0 \%)$ & \\
\hline & $>10$ years & $27(32.1 \%)$ & $28(42.4 \%)$ & $93(78.1 \%)$ & \\
\hline \multicolumn{2}{|c|}{ At least 1 (one) congress per year } & $61(72.6 \%)$ & $43(65.1 \%)$ & $72(60.5 \%)$ & 0.202 \\
\hline \multicolumn{2}{|c|}{$\geq 5$ events (arrests) per year } & $45(46.4)$ & $26(30.4)$ & $46(40.3)$ & 0.11 \\
\hline \multicolumn{2}{|c|}{$\geq 5$ hours of emergency duty per week } & $61(72.6 \%)$ & $36(54.5 \%)$ & $59(49.6 \%)$ & $<0.01$ \\
\hline
\end{tabular}

Table 2. Personal modifications and changes in the work environment caused by the Advanced Cardiac Life Support course according to time since taking the course, based in the survey.

\begin{tabular}{|c|c|c|c|c|}
\hline Time of ACLS & $<3$ years $(84)$ & $3-5$ years $(66)$ & $>5$ years $(119)$ & $\mathbf{p}$ \\
\hline \multicolumn{5}{|l|}{ Personal } \\
\hline Change in practice & $78(92.8 \%)$ & $61(92.4 \%)$ & $113(94.9 \%)$ & 0.741 \\
\hline Assurance in providing care & $79(94.0 \%)$ & $63(95.4 \%)$ & $113(94.95)$ & 0.923 \\
\hline Important role in providing care & $67(79.76 \%)$ & $46(69.7 \%)$ & $90(75.6 \%)$ & 0.363 \\
\hline Greater certainty about conducts & $80(95.2 \%)$ & $62(93.9 \%)$ & $113(94.9 \%)$ & 0.933 \\
\hline Took other ACLS courses & $26(30.9 \%)$ & $13(19.7 \%)$ & $23(19.3 \%)$ & 0.116 \\
\hline \multicolumn{5}{|l|}{ Environment } \\
\hline Purchase of an AED or defibrillator & $24(28.5 \%)$ & $14(21.2 \%)$ & $50(42.0 \%)$ & 0.01 \\
\hline Purchase of materials & $30(35.7 \%)$ & $18(27.2 \%)$ & $52(43.7 \%)$ & 0.081 \\
\hline Room reform & $20(23.8 \%)$ & $15(22.7 \%)$ & $35(29.4 \%)$ & 0.52 \\
\hline Training of a team & $67(79.7 \%)$ & $44(66.6 \%)$ & $92(77.3 \%)$ & 0.14 \\
\hline New AEDs in public places & $35(41.6 \%)$ & $19(28.7 \%)$ & $52(43.7 \%)$ & 0.12 \\
\hline
\end{tabular}

determine whether they would have an impact, but these variables proved to be non-significant and were removed from the final model due to sample limitation. Similarly, the variable working in a hospital was removed from the models because of collinearity with emergency work and number of arrests managed.

The second situation can be surprising because it seems to be contradictory. Although we have no literature data, we may infer that the 


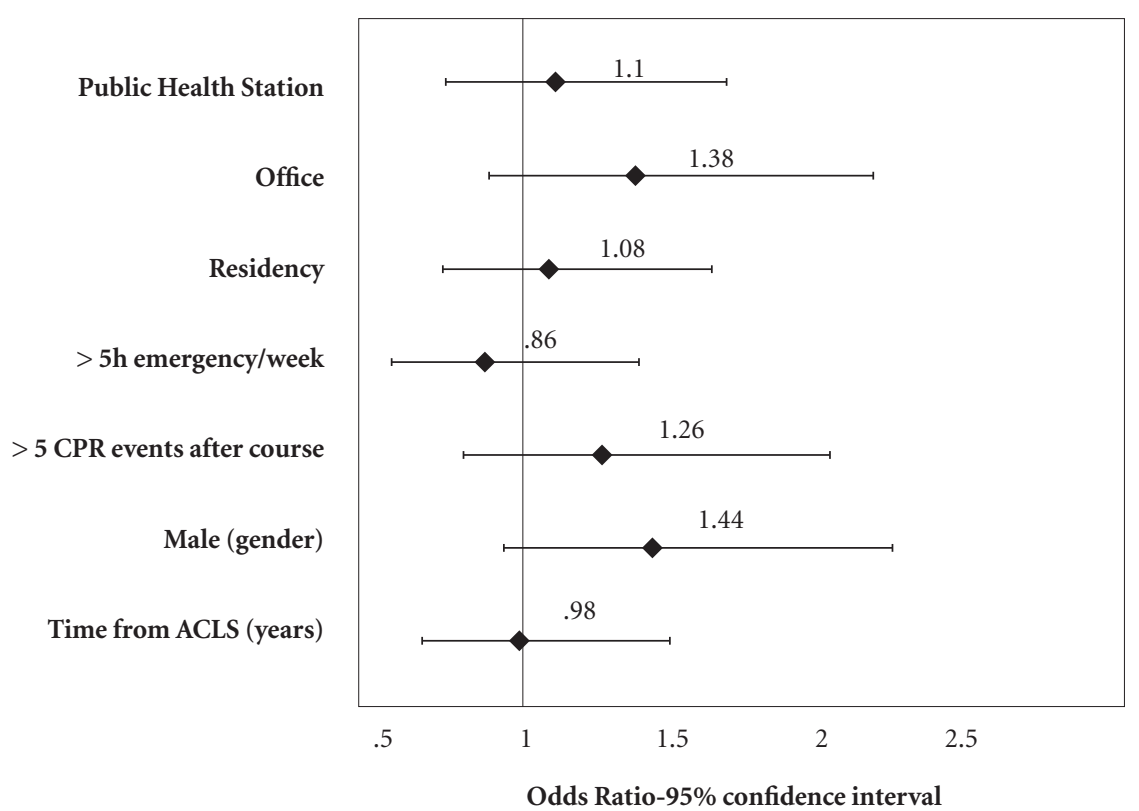

Figure 1. Odds Ratio and 95\% confidence interval for the predictive variables that lead an ACLS student to repeat the course, based in the survey.

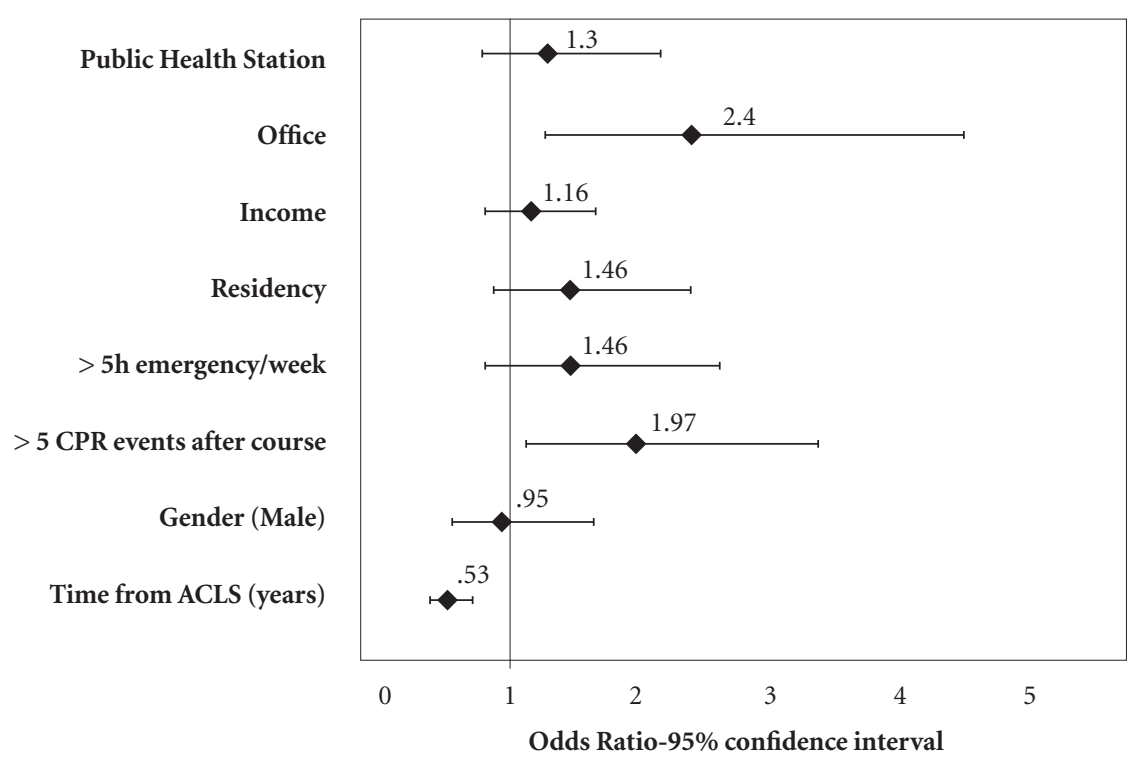

Figure 2. Odds Ratio and 95\% confidence interval for variables predicting that an ACLS student will help with the implantation of an AED in the community, based in the survey.

the arrival of advanced support at a doctor's office may be delayed ${ }^{14}$. In addition, the variable working in a public health station was not found to be significant and, since the risk of the popu- 
lation is the same, a similar behavior would be expected. This may not have occurred because a doctor does not feel the same responsibility in a public service that he feels in a private service.

A doctor would be expected to seek revalidation because of the appreciation of learning, especially in view of the periodic modifications occurring in the ACLS course every five years ${ }^{15}$. However, a previous study by our group showed that there is no significant difference between the course models applied, a fact that may suggest that doctors do not perceive an advantage of the modifications over a period of less than five years ${ }^{11}$. In the multivariable model, we observed that the chance of a doctor seeking revalidation is reduced with the passage of time.

With the same intention of assessing the social responsibility acquired by doctors who participate in the ACLS course, we sought to evaluate their attempts to modify the work environment. Although univariate analysis did not show statistical significance except for the purchase of AEDs, we observed that less than half the doctors became actively involved in modifying their place of work, with team training being the only exception. Since we did not explore the type of training provided or its characteristics, we could not assess its effectiveness, this being a limitation of the present study. Although frustrating, it is interesting to observe that doctors do not become actively involved in the change of environment. This may be due to the fact that they don't feel directly responsible, an inference supported by the comparison between those who work in public and private ambulatory services, or may be due to other factors such as the lack of political power in the institution or not being directly involved in emergency care. This finding should be confirmed and described in more detail in future studies.

Regarding the modification of the social environment in which the doctors operate, the only significant variable, again, was working in a private office. Again, we have no elements for the assessment of the degree of the doctor's involvement, but it seems likely that the growing judicialization of medicine and the proximity of the professionals who work in private community services are important factors for this decision. In addition, the involvement in this community work may be a form of medical marketing ${ }^{16}$. Once again, the fact that this is not observed in public health stations may demonstrate that lack of commitment of the physician to the public work environment.
Finally, the doctors may understand this to be the responsibility of administrators or of the government. There is no doubt that, when submitting to training in an ACLS course, a doctor is already fulfilling the function of keeping up to date in order to offer his best knowledge, but his ability to lead in the occupational and social environment is not aroused by the course.

Thus, it was observed that the training ins ACLS allows the learner to modify the environment, but limited to the acquisition and installation of AEDs in their workplace without modifying public places, the team that assists in service or modification of workplace. Moreover, only professionals with continuous ACLS practice - attending PCR on duty - do recycling despite its knowledge - although of AHA recommends update ever 2 years. Physicians who sought update are working in private practice instead of those working public service, either in emergency rooms or in basic health units. Unfortunately, these two public service gateways are precisely the places who would have a major impact over in public health. These finding is troublesome, since doctors working in these places would be less prompt to attend PCR.

\section{Limitations}

The present study has several limitations. Unfortunately, the response rate was low compared to the number of students trained, just $9,7 \%$ of all. This does not invalidate the interpretation of the data since all respondents were subjected to the same biases. It was also frustrating not to be able to deal more in depth with some questions, but the design of the instrument was focused on rapid filling out in order to stimulate the doctors to respond and to send the filled out document by mail. More elaborate questions might have reduced even more our sample.

\section{Conclusions}

In summary, the present findings apparently indicate that the ACLS course does not modify in a positive manner the occupational and social importance of these doctors as leaders for the strengthening of the survival chain, an important function that the course could offer, indirectly. This information should be considered in the elaboration of new versions of the ACLS course and in the search of interaction between the training centers and medical and governmental entities. 


\section{Collaborations}

LSL Azevedo, LG Ribeiro, A Schmidt and A Pazin-Filho have made substantive contributions to the study, and all authors endorse the data and conclusions, specifically: LSL Azevedo organized all preclinical data before sending the questionnaire and their responses after, LG Ribeiro organized the data in the form of the article and drafted for submission, A Schmidt and A Pazin-Filho were responsible for seeking and achieving funding for research and guidance of researchers.

\section{References}

1. Taniguchi D, Baernstein A, Nichol G. Cardiac arrest: a public health perspective. Emerg Med Clin North Am 2012; 30(1):1-12.

2. Luciano PM, Pazin-Filho A. Atendimento de arritmia cardíaca em emergência de hospital universitário terciário. Rev Bras Cardiol 2011; 24(4):1-8.

3. Moretti MA, Cesar LAM, Nusbacher A, Kern KB, Timerman S, Ramires JAF. Advanced cardiac life support training improves long-term survival from in-hospital cardiac arrest. Resuscitation 2007; 72(3):458-465.

4. Luciano PM, Matsuno AK, Moreira RSL, Schmidt A, Pazin-Filho A. Suporte Básico de Vida. Rev da Soc Cardiol do Estado São Paulo 2010; 20(2):230-238.

5. Einspruch EL, Lynch B, Aufderheide TP, Nichol G, Becker L. Retention of CPR skills learned in a traditional AHA Heartsaver course versus 30-min video self-training: a controlled randomized study. Resuscitation 2007; 74(3):476-486.

6. Capone PL, Lane JC, Kerr CS, Safar P. Life supporting first aid (LSFA) teaching to Brazilians by television spots. Resuscitation 2000; 47(3):259-265.

7. Potts J, Lynch B. The American Heart Association CPR Anytime Program: the potential impact of highly accessible training in cardiopulmonary resuscitation. $J$ Cardiopulm Rehabil 2006; 26(6):346-354.

8. Ribeiro LG, Germano R, Menezes PL, Schmidt A, Pazin-Filho A. Medical students teaching cardiopulmonary resuscitation to middle school Brazilian students. Arq Bras Cardiol 2013; 101(4):328-335.

9. Atkins DL. Realistic expectations for public access defibrillation programs. Curr Opin Crit Care 2010, 16(3):191-195.

10. Woollard M, Whitfield R, Newcombe RG, Colquhoun $M$, Vetter N, Chamberlain D. Optimal refresher training intervals for AED and CPR skills: a randomised controlled trial. Resuscitation 2006; 71(2):237-247.
11. Garrido FD, Romano MMD, Schmidt A, Pazin-Filho A. Can course format influence the performance of students in an advanced cardiac life support (ACLS) program? Brazilian J Med Biol Res 2011; 44(1):23-28.

12. Pazin-Filho A, Schmidt A, Filipini C, Barroso R, De Castro P, Rosa RM. Simulação de pacientes - Cursos de suporte de vida ACLS , BLS E PALS na FMRP - USP. Med (Ribeirão Preto) 2007; 40(2):204-212.

13. Mello MJ, Merchant RC, Clark MA. Surveying Emergency Medicine. Acad Emerg Med 2013; 20(4):409-412.

14. Adolfi Júnior MS, Pallini FM, Pessotti H, Wolf CM, Patelli HT, Capeli RD, Marques PM, Pazin-Filho A. Emergency medical coordination using a web platform: a pilot study. Rev Saude Publica 2010; 44(6):1063-1071.

15. Reynolds JC, Bond MC, Shaikh S. Cardiopulmonary resuscitation update. Emerg Med Clin North Am 2012; 30(1):35-49.

16. Alves FHC, Torres FP, Suto HS, Azevedo LSL, Barbosa MM, Pedro RM, Santana ACDA, Rantin D, Leonardo FHL, Andrade MG, Ferreira NN, Pazin-Filho A. Marketing Médico. Rev Bras Educ Med 2012; 36(3):293299.

Artigo apresentado em 05/09/2015

Aprovado em 21/06/2016

Versão final apresentado em 23/06/2016 